\title{
Nucleolar organizer regions in Sittasomus griseicapillus and Lepidocolaptes angustirostris (Aves, Dendrocolaptidae): Evidence of a chromosome inversion
}

\author{
Marcelo de Oliveira Barbosa ${ }^{1}$, Rubens Rodrigues da Silva ${ }^{1}$, Vanessa Carolina de Sena Correia ${ }^{1}$, \\ Luana Pereira dos Santos ${ }^{1}$, Analía del Valle Garnero ${ }^{2}$ and Ricardo José Gunski ${ }^{2}$ \\ ${ }^{1}$ Universidade Federal do Tocantins, Ciências Biológicas, Instituto de Biologia e Saúde Pública, \\ Laboratório de Genética, Porto Nacional, TO, Brazil. \\ ${ }^{2}$ Universidade Federal do Pampa, São Gabriel, RS, Brazil.
}

\begin{abstract}
Cytogenetic studies in birds are still scarce compared to other vertebrates. Woodcreepers (Dendrocolaptidae) are part of a highly specialized group within the Suboscines of the New World. They are forest birds exclusive to the Neotropical region and similar to woodpeckers, at a comparable evolutionary stage. This paper describes for the first time the karyotypes of the Olivaceous and the Narrow-billed Woodcreeper using conventional staining with Giemsa and silver nitrate staining of the nucleolar organizer regions (Ag-NORs). Metaphases were obtained by fibular bone marrow culture. The chromosome number of the Olivaceous Woodcreeper was $2 n=82$ and of the Narrow-billed Woodcreeper, $2 n=82$. Ag-NORs in the largest macrochromosome pair and evidence of a chromosome inversion are described herein for the first time for this group.
\end{abstract}

Keywords: cytogenetics, woodcreepers, Ag-NOR, chromosomal inversion.

Received: August 28, 2012; Accepted: November 23, 2012.

Brazil is home to approximately 1801 species of birds (CBRO) and is closely rivaled by Colombia and Peru in terms of biodiversity. The Dendrocolaptidae form a highly specialized group within the Suboscines of the New World, usually considered a sister group of the Furnariidae (Irestedt et al., 2002, 2004). They are reminiscent of woodpeckers at a similar evolutionary stage (Sick, 1997).

Cytogenetic studies in birds are still scarce compared to other vertebrates. Santos and Gunski (2006) pointed out that no more than $14 \%$ of the Brazilian species have been studied, leaving 38 families and three orders whose karyotypes have yet to be described. Few studies published on bird karyotypes characterize nucleolar organizer regions (NORs) with silver nitrate impregnation (Ag-NOR) or by fluorescence in situ hybridization (FISH) with $18 \mathrm{~S}$ and $28 \mathrm{~S}$ rDNA probes.

Using the silver impregnation technique, it has been shown that the Ag-NORs in the majority of birds studied are usually located in the microchromosomes and that the number of NOR-bearing microchromosomes is variable (Gunski and Giannoni, 1998; Garnero et al., 2006; Ledesma et al., 2006). Ag-NORs have also been described in the

Send correspondence to Ricardo J. Gunski. Universidade Federal do Pampa, Campus São Gabriel, Av. Antônio Trilha no 1847 , 97.300-000 São Gabriel, RS, Brasil. E-mail: rgunski@yahoo.com.br. macrochromosomes of Pitangus sulphuratus, Mimus saturninus (Passeriformes) and Guira guira (Cuculiformes) (Rocha and Lucca, 1988) and in the satellitized macrochromosomes of some species of the Accipitridae (Lucca, 1985). The aim of this study was to describe the karyotype of Sittasomus griseicapillus (olivaceous woodcreeper) and Lepidocolaptes angustirostris (narrow-billed woodcreeper) after conventional staining and silver nitrate impregnation to localize the Ag- NORs.

Two female specimens of $S$. griseicapillus and five of L. angustirostris (two females and three males) were analyzed. The samples were collected with mist nets in their natural environment in the central region of the State of Tocantins (TO), municipality of Porto Nacional, on the left bank of the Tocantins river $\left(10^{\circ} 45^{\prime} 15^{\prime}\right.$ ' $\mathrm{S}$ and $48^{\circ} 28^{\prime}, 51^{\prime}$ ' $\left.\mathrm{W}\right)$ under licenses 011/2004 and 191/2006 CGFAU - IBAMA process 02029.001756/2004-15. The biological material was deposited at the José Hidasi Zoological Museum in Porto Nacional - TO (voucher numbers: 13.814, 13.817 and 13.841) and at the Museu de Zoologia da Universidade de São Paulo (voucher numbers MZUSP 80.866, 80.883, 80.903 and 80.910).

Mitotic metaphases were obtained by directly culturing bone marrow from the fibula, according to Garnero and Gunski (2000). The preparations were Giemsa stained in a 
pH 6.8 phosphate buffer solution and at least 20 metaphases per specimen were analyzed to determine the diploid number and chromosome morphology.

The nucleolar organizer regions were detected with colloidal silver nitrate according to the protocol of Howell and Black (1980). The morphological classification of the chromosomes was performed following Guerra (1986).

S. griseicapillus had a diploid number of 82 chromosomes (Figure 1). The first ten pairs were considered macrochromosomes and the other 31 pairs, microchromosomes. Among the autosomal macrochromosomes, pair 3 was acrocentric and all the other nine pairs were telocentric. Pairs 1 and 2 were of similar length. The $\mathrm{Z}$ chromosome was acrocentric and had the same size as pairs 4 and 5. The $\mathrm{W}$ chromosome was a small telocentric equivalent in size to pairs 8 and 9. The largest telocentric pair had a subcentromeric secondary constriction (Figure 1) where the Ag-NOR was located (Figure 2).

L. angustirostris had a diploid number of 82 chromosomes (ten macrochromosome pairs and 31 microchromosome pairs) (Figure 3). Chromosomes pairs 1, 3 and 4 were acrocentric, whereas the other autosomal macrochromosomes were telocentric. Pair 1 had satellitized short arms. The $\mathrm{Z}$ chromosome was an acrocentric of the same size as pairs 4 and 5 and the $\mathrm{W}$ chromosome was a small telocentric. The Ag-NORs were located in the largest chromosome pair (Figure 4).

This is the first karyotype description from species of the family Dendrocolaptidae. Although they belong to different genera, S. griseicapillus and L. angustirostris exhibited similar karyotypes in terms morphology, with predominantly telocentric chromosomes and only a few acrocentrics. This is in contrast with observations in other

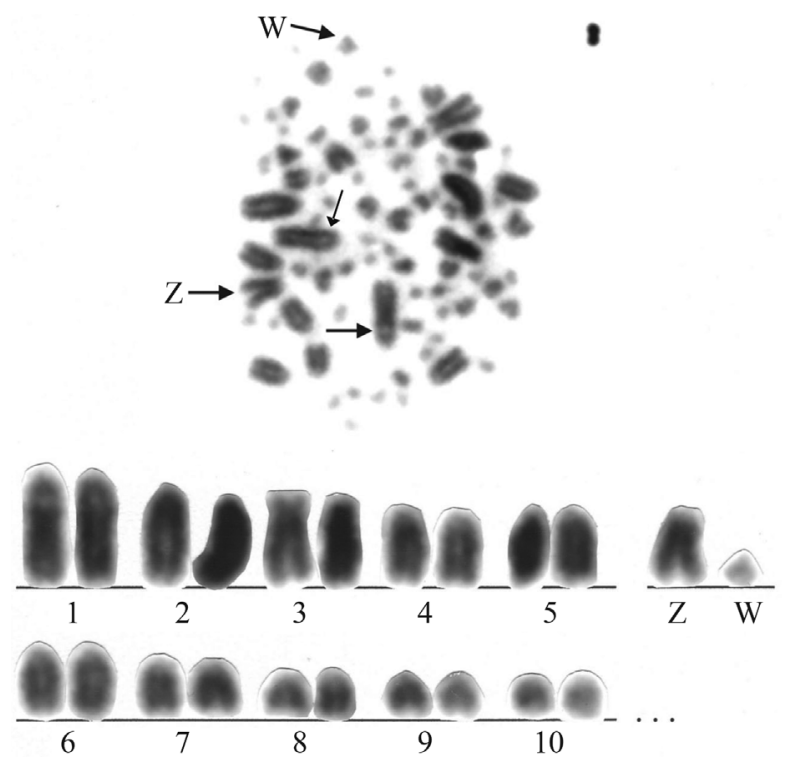

Figure 1 - Metaphase and partial karyotype of a female specimen of Sittasomus griseicapillus $(2 \mathrm{n}=82)$. The thin arrow indicates the secondary constriction.
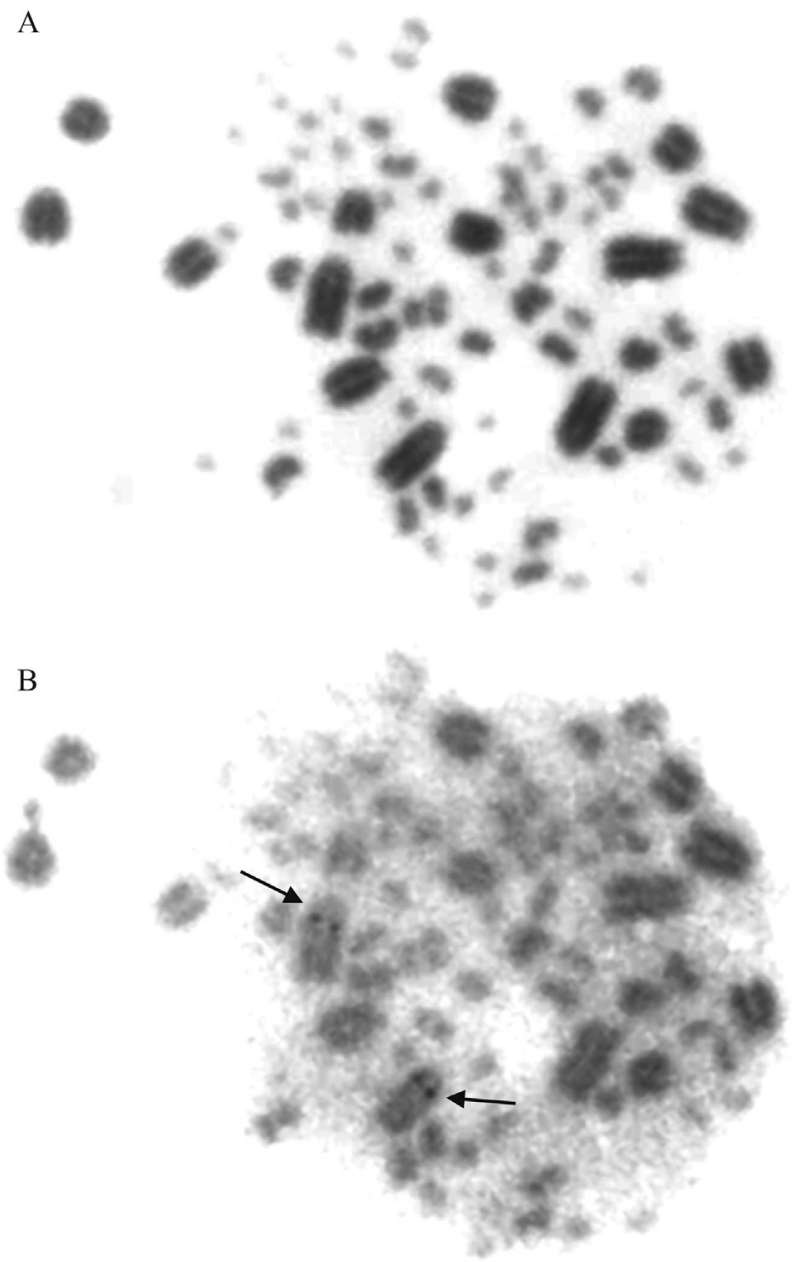

Figure 2 - Giemsa - Ag-NOR sequential staining of a metaphase of Sittasomus griseicapillus ( $2 \mathrm{n}=82)$ : (A) conventional Giemsa staining, (B) Ag-NOR staining.

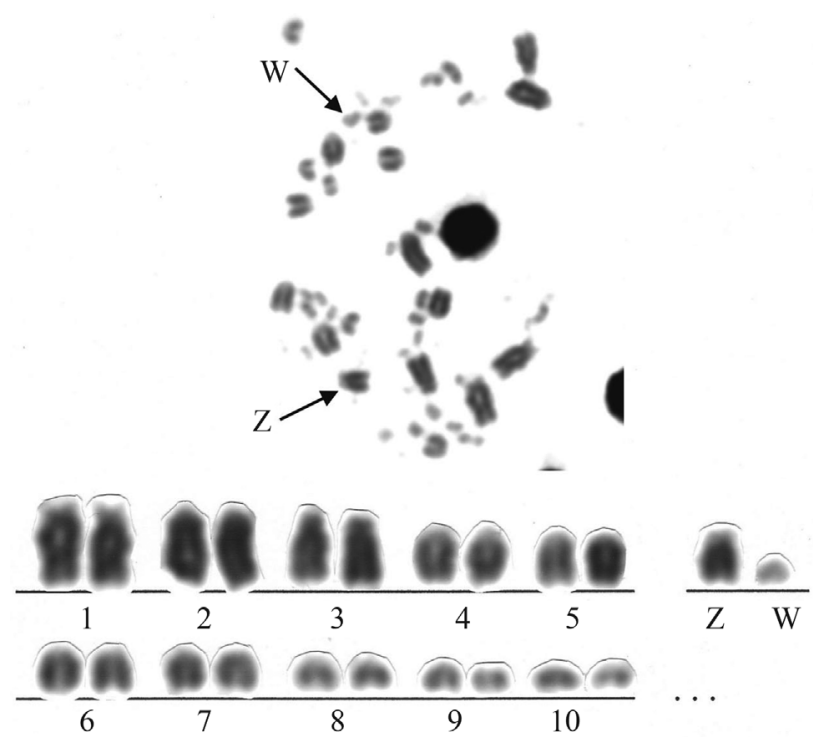

Figure 3 - Metaphase and partial karyotype of a female specimen of Lepidocolaptes angustirostris $(2 \mathrm{n}=82)$. 
A
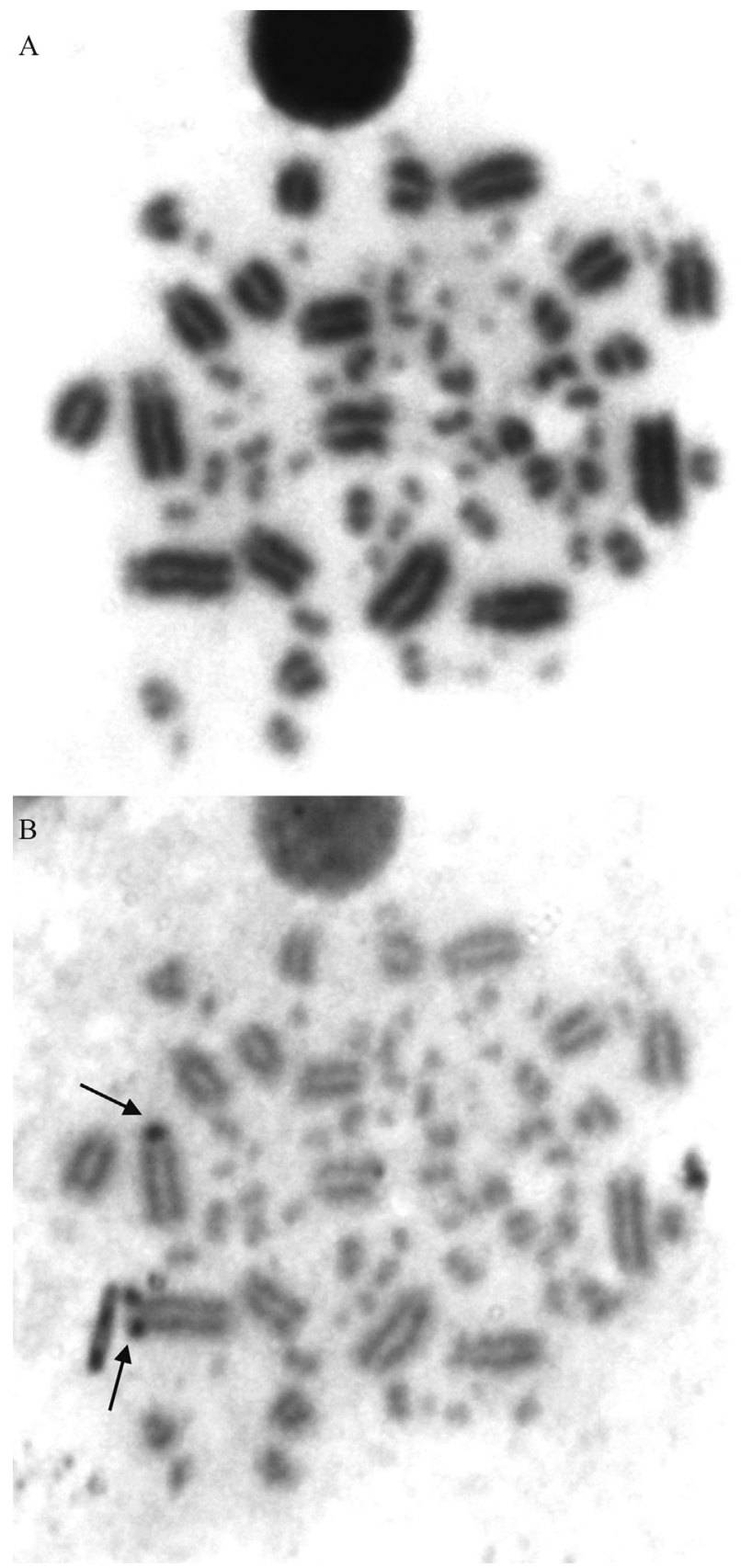

Figure 4 - Giemsa - Ag-NOR sequential staining of a metaphase of Lepidocolaptes angustirostris $(2 \mathrm{n}=82)$. (A) conventional Giemsa staining, (B) Ag-NOR staining.

Passeriformes families, in which some chromosomes are metacentric/submetacentric. Only pairs 1 and 4 differed in morphology between the two species. The diploid numbers were in accordance to those usually observed in the order Passeriformes (around 80 chromosomes).

The species of Dendrocolaptidae analyzed herein had karyotypes similar to those of Furnarius rufus and Lochmias nematura, which belong to the family Furnariidae, considered a sister group of Dendrocolaptidae and are the only known species of Furnariidae that have been karyotyped (Lucca and Rocha, 1992). F. rufus and $L$. nematura have predominantly telocentric and a few acrocentric chromosomes, morphologically very similar to the chromosomes of the species that we studied.

The presence of Ag-NORs in pair 1, the largest macrochromosome pair, is described herein for the first time in the class Aves (Figures 2 and 4). Previous studies showed that Ag-NORs were associated with secondary constrictions on macrochromosomes equivalent in size to pair 9 in Pitangus sulphuratus (Passeriformes) and Guira guira (Cuculiformes), to pair 3 of Mimus saturninus (Passeriformes) (Rocha and Lucca, 1988), and in the secondary constrictions forming the satellite on pair 7 of Buteo albicaudatus (Accipitridae) (Lucca, 1985).

The presence of NORs in the largest macrochromosome pair of Dendrocolaptidae species further substantiates the fact that not only microchromosomes and smaller macrochromosomes are responsible for nucleolar organization in Aves. It is possible that additional species in this group exhibit NORs in the largest macrochromosomes.

The largest chromosomes of S. griseicapillus and $L$. angustirostris underwent a chromosome inversion that altered their morphology and changed the position of the NOR. The presence of constitutive heterochromatin close to the NOR may have facilitated rearrangements in this region (Lucca, 1985). Our results point towards possible chromosome rearrangements that need confirmation by further Ag-NORs analyses of additional populations and specimens.

\section{Acknowledgments}

Our thanks go to Mr. José de Oliveira Negre, owner of the Gruta da Serra farm, for his kindness in allowing us to collect samples on his land, to colleagues at the Instituto de Biologia e Saúde Pública at the Universidade Federal do Tocantins (UFT) and to the University, to our colleague Mário Angel Ledesma for his guidance and contributions to the study, to the Brazilian Environment Agency (IBAMA) for the licenses to collect samples, to the National Council for Scientific and Technological Development (CNPq) and the Tocantins State Agency for Science and Technology (SECT-TO) for funding the study, and to all those who contributed to our work in any way.

\section{References}

Garnero A del V and Gunski RJ (2000) Comparative analysis of the karyotypes of Nothura maculosa and Rynchotus rufescens (Aves, Tinamidae). A case of chromosomal polymorphism. The Nucleus 43:64-70.

Garnero A del V, Ledesma MA and Gunski RJ (2006) Alta homeologia cariotípica na família Tinamidae (Aves, Tinamiformes). Rev Brasil Ornitol 14:53-58.

Guerra M (1986) Reviewing the chromosome nomenclature of Levan et al. Rev Bras Genet 9:741-743. 
Gunski RJ and Giannoni ML (1998) Nucleolar organizer regions and new chromosome number for Rhea americana (Aves, Rheiformes). Genet Mol Biol 21:207-210.

Howell WM and Black DA (1980) Controlled silver staining of nucleolus organizer regions with a protective colloidal developer: A 1-step method. Experientia 36:1014-1015.

Irestedt M, Fjeldsa J and Ericson PGP (2002) Systematic relationships and biogeography of the tracheophone suboscines (Aves, Passeriformes). Mol Phylogenet Evol 23:499-512.

Irestedt M, Fjeldsa J and Ericson PGP (2004) Phylogenetic relationships of woodcreepers (Aves, Dendrocolaptinae) - Incongruence between molecular and morphological data. $\mathrm{J}$ Avian Biol 35:208-288.

Ledesma MA, Martinez PA, Calderón OS, Boeris JM and Meriles JM (2006) Descrição do cariótipo e padrões de bandas C e NOR em Pheucticus aureoventris (Emberizidae, Cardinalinae). Rev Brasil Ornitol 14:59-62.
Lucca EJ (1985) Kariotype and nucleolus organizing regions in chromosomes of the white-tailed hawk, Buteo albicaudatus (Falconiformes, Aves). Cytobios 42:7-13.

Lucca EJ and Rocha GT (1992) Citogenética de aves. Bol Mus Paran Emilio Goeldi Ser Zool 8:33-67.

Rocha GT and Lucca EJ (1988) Nucleolar organizer regions in somatic chromosomes of some species of birds. Caryologia 41:299-308.

Santos LP and Gunski RJ (2006) Revisão de dados citogenéticos sobre a avifauna brasileira. Rev Brasil Ornitol 14:35-45.

Sick H (1997) Ornitologia Brasileira, Edição Revista e Ampliada por José Fernando Pacheco. Ed Nova Fronteira, Rio de Janeiro, $862 \mathrm{pp}$.

\section{Internet Resources}

CBRO Lista de Aves do Brasil. 10 edição. http://www.cbro.org.br (February 10, 2012).

Associate Editor: Yatiyo Yonenaga-Yassuda

License information: This is an open-access article distributed under the terms of the Creative Commons Attribution License, which permits unrestricted use, distribution, and reproduction in any medium, provided the original work is properly cited. 